\title{
Firing Rate of Nucleus Accumbens Neurons Is Dopamine- Dependent and Reflects the Timing of Cocaine-Seeking Behavior in Rats on a Progressive Ratio Schedule of Reinforcement
}

\author{
Saleem M. Nicola and Sam A. Deadwyler \\ Center for the Neurobiological Investigation of Drug Abuse, Department of Physiology and Pharmacology, Wake Forest \\ University School of Medicine, Winston-Salem, North Carolina 27157
}

The progressive ratio $(\mathrm{PR})$ schedule of reinforcement is used to determine the reinforcing properties of rewards such as drugs of abuse. In this schedule, the animal is required to press a lever a progressively increasing number of times to receive a reward; the highest ratio obtained before the animal ceases responding is termed "breakpoint." We recorded neuronal spike activity from cells in the nucleus accumbens (NAc) of rats responding on a PR schedule for cocaine reinforcement. A common subtype of NAc cells demonstrated firing rates that varied according to the time between cocaine deliveries. The firing rate was inversely related to the NAc cocaine level predicted by a pharmacokinetic model. At higher response-to-reward ratios, inter-reward intervals were increased, resulting in a decrease in modeled cocaine level and a concomitant increase in firing rate over the session. The final increase in firing rate above a threshold value suggests a neural correlate of breakpoint. The effects of preadministration of dopamine D1 or D2 antagonists on the animals' behavior were similar in that both reduced breakpoint; however, each antagonist had markedly different effects on NAc cell firing. The D1 antagonist $\mathrm{SCH} 23390$ reduced firing rates, even at low cocaine levels, whereas the D2 antagonist eticlopride induced a rightward shift in the dose dependence of NAc cell firing relative to modeled cocaine level. Our results suggest that the firing of NAc cells reflects changes in cocaine levels and thereby contributes to the temporal spacing of self-administration and to the cessation of responding at breakpoint.

Key words: progressive ratio; cocaine; nucleus accumbens; dopamine; reward; multiunit recording; addiction; self-administration; D1 receptors; $D 2$ receptors
In the progressive ratio (PR) schedule of reinforcement, the number of operant responses required to obtain a reward is increased with each successive reward obtained, until the animal ceases to respond. The pioneering work of Hodos (1961) established the use of the highest number of responses ("breakpoint") as a measure of the rewarding value of the reinforcer. Breakpoints were found to decrease with decreasing nutritional value of a food reward and increase with greater food deprivation (Hodos, 1961; Hodos and Kalman, 1963). These findings have since been extended to other types of reinforcers, most notably drugs of abuse (Richardson and Roberts, 1996; Arnold and Roberts, 1997). For instance, varying the unit dose of psychostimulants, such as cocaine, results in a corresponding change in breakpoint such that higher breakpoints are obtained with higher subtoxic doses and lower breakpoints with lower doses of cocaine (Bedford et al., 1978; Griffiths et al., 1978; Risner and Silcox, 1981; Risner and Goldberg, 1983; Winger and Woods, 1985; Risner and Cone, 1986; Roberts et al., 1989; Depoortere et al., 1993; Li et al., 1994; McGregor et al., 1996).

Studies in which D1 or D2 dopamine (DA) receptor antagonists were systemically administered have found substantially reduced breakpoints in animals responding for psychostimulant reward (Risner and Cone, 1986; Roberts et al., 1989; Hubner and Moreton, 1991; Depoortere et al., 1993; Richardson et al., 1994; Smith et al., 1995). Furthermore, a reduction in breakpoint for cocaine reward was observed when D1 antagonists were directly administered into

Received Dec. 21, 1999; revised April 27, 2000; accepted May 1, 2000.

This work was supported by National Institute on Drug Abuse Grants DA05832 to S.M.N. and DA11486, DA06634, and DA00119 to S.A.D. We are grateful for the expert technical assistance of Joanne Konstantopoulos and to Drs. Robert Hampson and Tom Smulders for helpful discussions.

Correspondence should be addressed to Dr. Sam A. Deadwyler, Department of Physiology and Pharmacology, Medical Center Boulevard, Wake Forest University School of Medicine, Winston-Salem, NC 27157. E-mail: sdeadwyl@wfubmc.edu.

Dr. Nicola's present address: Department of Neurology, Ernest Gallo Clinic and Research Center, University of California, San Francisco, 5858 Horton Street, Suite 200, Emeryville, CA 94608. E-mail: nicola@phy.ucsf.edu.

Copyright (C) 2000 Society for Neuroscience 0270-6474/00/205526-12\$15.00/0 the nucleus accumbens (NAc) or prefrontal cortex (McGregor and Roberts, 1993, 1995), both of which receive major dopaminergic projections from the ventral tegmental area (Heimer et al., 1997). Together with findings of elevated dopamine levels within the NAc during cocaine self-administration (Pettit and Justice, 1989; Gratton and Wise, 1994; Wise et al., 1995; Hemby et al., 1997), the above reports are consistent with the hypothesis that DA (levels of which are elevated in the NAc as a result of blockade of DA uptake by cocaine) is of primary importance in mediating psychostimulant reinforcement. Furthermore, they suggest that NAc DA may participate in determining when breakpoint occurs.

The relationship between breakpoint and the value of a reinforcer provides a unique tool for examining the mechanisms of reinforcement. Little is known about the precise role played by the NAc in determining reinforcing value. To examine how cell firing within the NAc is related to breakpoint and the value of cocaine reward, we used multiple-electrode arrays to record from cells in the NAc of rats subjected to a PR schedule of cocaine reinforcement. We administered systemic DA antagonists to determine how firing patterns of NAc cells are affected by the antagonist-induced reduction in cocaine reward efficacy.

\section{MATERIALS AND METHODS}

Animals surgery and behavior. Male Sprague Dawley rats (Harlan Sprague Dawley, Indianapolis, IN) weighing 350-450 gm were used for these experiments. Animals were treated in accordance to Guide for the Care and Use of Laboratory Animals published by the United States Public Health Service. Food and water were restricted to maintain body weight at a constant level ( $~ 85 \%$ of ad libitum weight). Each animal was implanted under ketamine $(100 \mathrm{mg} / \mathrm{kg})$ and xylazine $(10 \mathrm{mg} / \mathrm{kg})$ anesthesia with a jugular catheter as described previously (Carelli et al., 1993; Carelli and Deadwyler, 1994). Catheters were constructed of small bore tubing so that the "dead volume" $(<0.01 \mathrm{ml})$ was small relative to the volume of drug solutions injected during self-administration $(0.2 \mathrm{ml})$. Patency of catheters was maintained by daily flushing with heparinized $(5 \mathrm{U} / \mathrm{ml})$ saline. After 1 week of recovery, catheterized animals were trained to self-administer cocaine (0.33 mg/infusion) using a fixed-ratio 1 (FR1) schedule. The behavioral chamber consisted of a sound- and light-proof box containing an inner Plexiglas chamber equipped with constant white noise, an operant 
response lever, and a cue light $6.5 \mathrm{~cm}$ above the lever. When the animal pressed the lever, cocaine was delivered over $\sim 6 \mathrm{sec}$, and the animal received a $20 \mathrm{sec}$ time-out during which the cue light was extinguished, house lights were turned on, and a $67 \mathrm{~dB}, 1 \mathrm{kHz}$ tone was presented.

Once stable lever pressing on the FR1 schedule was attained, animals were stereotaxically implanted with microwire arrays as described below. After 1 week of recovery, animals were allowed access to cocaine in the behavioral chamber. Upon re-establishment of stable responding for cocaine under FR1, the dose of cocaine was increased to $0.75 \mathrm{mg} /$ infusion, and animals were provided with an automatic priming injection of cocaine if no lever presses were made within $5 \mathrm{~min}$ of the start of the session. Animals were subjected to a progressive ratio protocol under which the number of times the animal was required to press the lever to receive one dose of cocaine was increased with each reward according to the function

\section{Required Leverpresses $=5 e^{i k}-5$}

Where $i$ is the reward number, and $k$ is a constant (Richardson and Roberts, 1996). For our experiments $k=0.3$ in most cases, resulting in the following progression of required lever presses: $1,2,4,7,12,17,25,36,50$, $69,95,131,178,242,328,445,603,815$, and 1102 (Fig. $1 D$ ). The session was terminated after the animal failed to respond for at least $10 \mathrm{~min}$ longer than the longest inter-reward interval (IRI); "breakpoint" for the session was defined as the animal's last lever press of the session (which was not rewarded). Before beginning the drug treatments described below, untreated sessions were run until consistent performance (no changes in breakpoint larger than three rewards from day to day) on the PR schedule was obtained.

The DA receptor antagonists SCH23390 (D1) or eticlopride (D2) (Research Biochemicals, Natick, MA) or vehicle controls, were administered subcutaneously thirty min before all PR sessions. Each animal was subjected to one session per day, and vehicle control sessions were alternated with drug sessions. Drugs were given in increasing doses, and in most cases, at least two sessions at each dose were obtained for each animal. Performance on the PR schedule was monitored from day to day. Control sessions in which substantial (more than three rewards different from previous day) changes in breakpoint occurred (as well as drug sessions occurring the previous day) were eliminated from the analysis; the animal was then subjected to control sessions only until breakpoint behavior became consistent from day to day. Stock solutions of the DA antagonists were made daily by directly dissolving in saline and then diluting to the appropriate dose level $(10,20$, or $40 \mu \mathrm{g} / \mathrm{kg}$ for each drug).

Cocaine level model. NAc cocaine levels were modeled (Figs. 4, 6, 7) as described by Pan et al. (1991) for intravenous cocaine injections in rats. For a single injection of cocaine, NAc cocaine level was computed as

$$
C=d A\left(e^{-\alpha t}-e^{-\beta t}\right)
$$

where $C$ is the cocaine concentration (micromolar), $d$ is the cocaine dose (milligrams per kilogram), $A$ is a constant that equals $9.637 \mu \mathrm{M}$. $\mathrm{kg} \cdot \mathrm{min}^{-1} \cdot \mathrm{mg}^{-1}, \alpha$ is a constant that equals $0.642 \mathrm{~min}^{-1}, \beta$ is a constant that equals $0.097 \mathrm{~min}^{-1}$, and $t$ is the time (in minutes) since the injection occurred. Constants were obtained from Pan et al. (1991) for rats chronically exposed to cocaine. For more than one injection of cocaine, as occurred in all self-administration sessions, the instantaneous cocaine concentration at any time $T$ during the session was computed as the sum of all values of $C$ for all cocaine injections received before $T$. The plot of cocaine level over time in Figure $4 A$ was computed by dividing a representative session into 0.5 min time bins and computing the instantaneous cocaine concentration at the end of each bin (i.e., treating each bin as a separate time $T$ ). In Figure $4 B$, the cocaine level was computed in the same way, except that (1) the bin width was $0.1 \mathrm{~min}$, and (2) the times at which cocaine injections were set to occur were not based on a single session but rather on the average inter-reward intervals for PR or FR sessions across all animals and sessions.

Electrophysiological recording and data analysis. Electrode arrays (NB Labs, Denison, TX) consisted of eight $50 \mu \mathrm{m}$ stainless steel wires separated by $0.25-0.5 \mathrm{~mm}$ and a silver ground wire that was implanted in the brain caudal to the NAc. Target coordinates for the array (relative to bregma and the top of the skull) were anteroposterior $1.5-1.7 \mathrm{~mm}$, mediolateral $\pm 1.5 \mathrm{~mm}$, and dorsoventral 5.9-6.9 mm (Paxinos and Watson, 1986). Miniature plug-in connectors were embedded in cranioplastic cement on top of the skull. Before recording sessions, a cable with a head stage containing unity gain field effect transistors (NB Labs) was connected to the electrodes. Whenever possible, the signal from an inactive (no detectable cell) electrode was subtracted from the signals from other, active electrodes (differential recording) to minimize noise. Signals were amplified and filtered, and spikes were sorted on-line using a Neurophysiological Event Processor (Plexon Inc., Dallas, TX). Custom written software allowed for integration of unit firing data and behavioral event data in a single time-stamped master file. In most cases, individual neurons could be recorded over many days. To ensure that the same neuron was recorded on successive days, the shape of the waveform was carefully compared with the waveform from the previous day. Firing parameters [such as autocorrelograms, overall firing rate, perievent histograms (PEHs), and strip charts] were also compared for control sessions from day to day, and if these changed substantially, the cell was eliminated from the analysis starting with the drug session of the previous day.

Data analysis consisted of comparisons of firing rates at different phases of the session and of PEHs and comparisons of the effects of systemically administered drugs on these measures. Separate two-way ANOVAs for each dose of a DA antagonist were used to compare firing rates in the presence and absence of the antagonist at various times (Fig. 8). The data used for each comparison consisted of cell firing rates from all cells exposed to a given dose of the antagonist, both during the presence of the antagonist and in vehicle control sessions. ANOVAs therefore revealed whether there were overall significant effects of the antagonist and of the time during the session time or PEH, and of a significant effect of the antagonist on the effect of the session or PEH time on the firing rate. Because three separate ANOVAs were performed on overlapping data sets (most cells were exposed to more than one dose of the antagonist), a Bonferroni correction was applied by reducing the significance level from $p<0.05$ to $p<0.017$ (which is 0.05 divided by 3 ). Only rewards obtained after load up were used for PEH analyses.

The effects of DA antagonists on cocaine level versus firing rate doseresponse curves were computed using two-way ANOVAs. Sessions were divided into 1 min bins, and cocaine level was computed for each bin using the cocaine level model described above. Bins for all cells and all sessions in a particular DA antagonist or in vehicle control were then sorted by computed cocaine level, and averages of the firing rate across all bins within successive $5 \mu \mathrm{M}$ cocaine level increments were made to compute the graphs shown in Figures $6 D-F$, and $7 D-F$. The firing rates from each bin were used to compute two-way ANOVAs to determine the effect of DA antagonists on the dose-response curve; results of the ANOVAs were Bonferroni-corrected as described above.

Tukey, Student-Newman-Keuls, or Dunnett tests were used for post hoc comparisons of means. The effects of drugs on the slopes of firing rates plotted against time were compared using analysis of covariance as described by Zar (1974). Except in the instances noted above in which the Bonferroni correction was applied, $p<0.05$ was considered significant. All errors are expressed as the SEM. SigmaStat (SPSS Inc., Chicago, IL) software was used for all tests.

Histology. After the last experiment, each animal was deeply anesthetized with sodium pentobarbital $(50 \mathrm{mg} / \mathrm{kg})$, and a $20 \mu \mathrm{A}$ current was passed for $15 \mathrm{sec}$ through each electrode from which cell firing data had been recorded. The animal was then perfused with $10 \%$ formalin, and the brain removed, cryoprotected, and cut into $40 \mu \mathrm{m}$ sections with a microtome. All sections were stained with thionin and counterstained with potassium ferricyanide, which revealed a Prussian blue reaction product at electrode tips through which current had been passed (Green, 1958).

\section{RESULTS}

\section{Cell types recorded during progressive ratio sessions}

\section{Histology}

For this study, eight rats were implanted bilaterally with electrode arrays in the NAc. Examination of sections from the brains of all animals revealed that all electrode track terminations and all Prussian blue deposits at electrode tips were within the NAc or, more rarely (two tracks in one hemisphere of one animal, which likely corresponds to no more than two cells), in the rostroventral area of the dorsal striatum bordering the NAc.

\section{Behavior during progressive ratio sessions}

During both FR and PR sessions, animals were required to press a lever to receive a $0.75 \mathrm{mg} / \mathrm{inf}$ usion cocaine injection reward. Ten lever presses were required in FR sessions, whereas in PR sessions, the number of lever presses required was increased according to an exponential function as the session progressed (see Materials and Methods). At the beginning of both types of sessions, all animals exhibited load up behavior (Pettit and Justice, 1989; Carelli and Deadwyler, 1996a), defined as a period of rapid, erratic IRIs before the slower, more evenly spaced rewards obtained during the remainder of the session (Fig. 1C). Load up behavior was very common, occurring in $>90 \%$ of sessions. Animals were automatically given a priming dose of cocaine 5 min after the start of the session if the animal did not press the lever in that time. Consistent with previous findings (Roberts et al., 1989; Depoortere et al., 1993; Richardson and Roberts, 1996), animals on PR reached breakpoint (defined in Materials and Methods) after obtaining an average, across all animals, of $12.9 \pm 0.3$ rewards $(n=67$ sessions from 


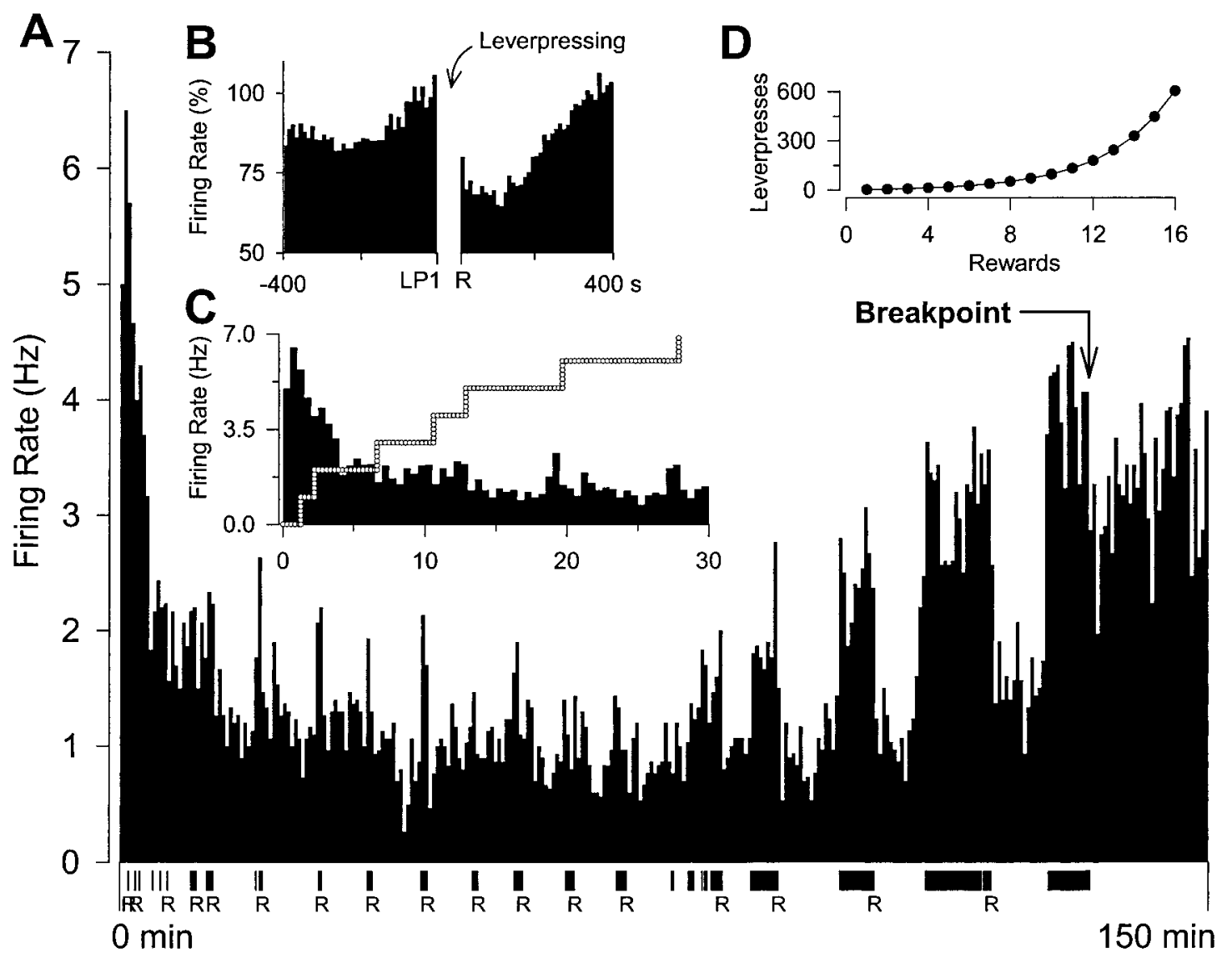

Figure 1. A typical LPE cell firing pattern during a PR session. A, Strip chart of an LPE cell during a PR session demonstrating reduction in firing rate accompanying load up and increasing firing rate as the animal approaches breakpoint. Vertical dashes along the abscissa indicate lever presses; $R$ indicates cocaine $(0.75 \mathrm{mg}$ /inf usion) reward. Bin width is $30 \mathrm{sec}$. $B$. PEH summarized across all LPE cells. Left shows firing rate for 6.7 min before the first lever press of each bout of lever pressing; right shows firing rate from reward delivery to 6.7 min after. All bins were normalized to the 30 sec preceding the onset of lever pressing. Bin width is $10 \mathrm{sec}$. $C$, Expanded first $30 \mathrm{~min}$ of strip chart shown in A. Vertical ticks of the dotted line denote time at which a reward was received. Load up in this session was the initial $15 \mathrm{~min}$ of relatively rapid accumulation of rewards. $D$, Plot of the number of lever presses required to obtain a reward as a function of reward number. In the session depicted in $A$, the animal received 16 rewards.

seven rats), which corresponds to an average breakpoint of $190 \pm$ 20 lever presses.

\section{Nucleus accumbens cell firing patterns during progressive ratio experiments}

Extracellular single neuron activity during PR sessions was recorded from a total of 97 cells (Table 1). Two main firing patterns in relation to lever pressing were observed. Lever press-excited (LPE) cells (32 of 97 neurons) exhibited an increase $(>15 \%)$ in firing rate during lever pressing compared with the rate during the reward lever press interval (RLI) (Figs. 1 $A, 2 A$ ). Lever pressinhibited (LPI) cells, defined by a decrease $(>15 \%)$ in firing rate during lever pressing compared with the RLI (Fig. $2 B$ ), were much less common $(n=10)$; despite their relative rarity, at least one LPI cell was observed in every animal recorded. The remaining cells, with $<15 \%$ difference between firing during lever pressing and during the RLI, were classified as "other" (Table 1) and were not phasic.

One characteristic of LPE cells (but not LPI cells) was a dramatic reduction in firing rate that occurred during load up (Fig. 1C) (Carelli and Deadwyler, 1996a; Peoples et al., 1998b; Carelli et al., 1999). The average firing rate in a $60 \mathrm{sec}$ window beginning $20 \mathrm{sec}$ after the reward that terminated load up was $65 \pm 5 \%$ lower than the firing rate measured from the beginning of the session before the first dose of cocaine $(n=32)$. No such reduction was apparent in LPI cells $(24 \pm 44 \%$ higher after load up than presession, $n=$ 10). The reduction in firing rate of LPE cells at load up was reversed gradually over the session. By the time the animal achieved breakpoint, the average firing rate (measured during a 60
Table 1. Nucleus accumbens cell types observed during progressive ratio

\begin{tabular}{lcccr} 
& LPE cells & LPI cells & Other & Total \\
\hline Number & 32 & 10 & 55 & 97 \\
$\%$ & $33 \%$ & $10 \%$ & $57 \%$ & $100 \%$ \\
\hline
\end{tabular}

\begin{tabular}{llll} 
& & LPE cells & Animals \\
\hline SCH23390 & Saline controls & 15 & 5 \\
& $10 \mu \mathrm{g} / \mathrm{kg}$ & 12 & 4 \\
& $20 \mu \mathrm{g} / \mathrm{kg}$ & 11 & 5 \\
& $30-50 \mu \mathrm{g} / \mathrm{kg}$ & 13 & 5 \\
Eticlopride & Saline controls & 19 & 4 \\
& $10 \mu \mathrm{g} / \mathrm{kg}$ & 14 & 4 \\
& $20 \mu \mathrm{g} / \mathrm{kg}$ & 18 & 4 \\
& $40 \mu \mathrm{g} / \mathrm{kg}$ & 12 & 3 \\
\hline
\end{tabular}

sec window after the last lever press) was $56 \pm 8 \%$ higher than postload up rate. Again LPI cells did not exhibit this difference (37 $\pm 43 \%$ lower at breakpoint than postload up).

The firing rates of LPE cells tended to increase gradually in the 5 min before the onset of each bout of lever pressing (Figs. 1B, 2A). LPI cell firing rates exhibited a striking reciprocity to the LPE pattern; during times within the session when LPE cell firing rates were increasing, LPI cell firing rates were decreasing (Fig. 2). For LPE cells, the peak firing rate occurred during lever pressing, 


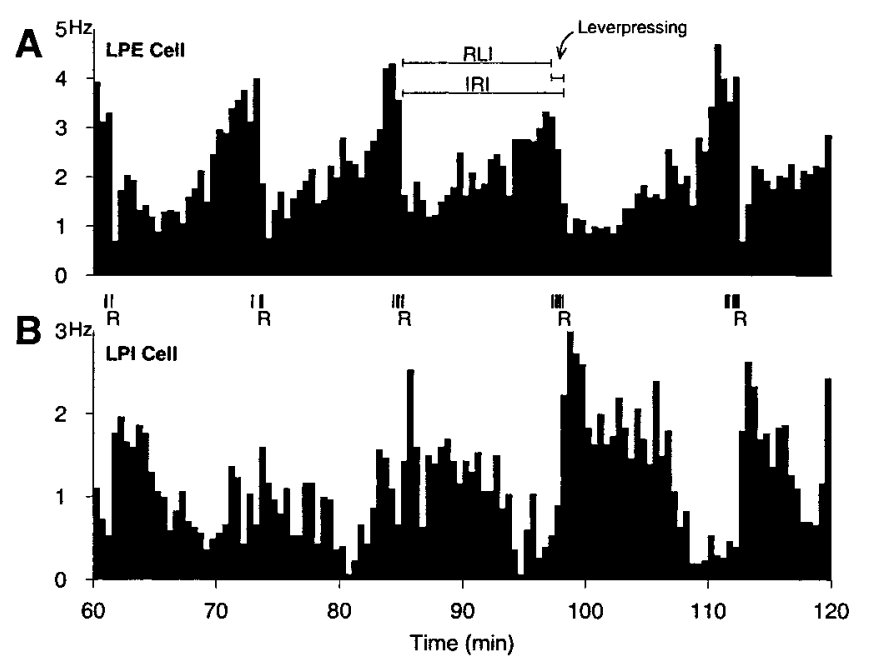

Figure 2. Strip charts of the firing rates of an LPE $(A)$ and an LPI $(B)$ cell recorded simultaneously during a PR session. Bin width for both plots is 30 sec. Vertical dashes indicate lever presses; $R$ indicates receipt of reward. $R L I$ stands for reward to first lever press interval, and IRI stands for interreward interval; the difference is that the $I R I$ includes lever pressing.

whereas for LPI cells, the peak occurred between the reward and the onset of the next bout of lever pressing. On average, the firing peak for LPI cells occurred 5 min after receipt of the reward (data not shown). After reaching its peak, the firing rate of LPI cells gradually declined over 2-3 min until the onset of the next bout of lever pressing, during which firing rates were lowest. LPE cells, however, demonstrated a much more rapid reduction in firing; the transition from the highest firing rates (during lever pressing) to lowest rates occurred within $15 \mathrm{sec}$ of the cocaine reward (Figs. $1,2 A)$.

\section{Nucleus accumbens cell firing correlates of breakpoint}

The overall firing rate of LPE cells gradually increased as the session progressed, reaching the highest levels during and after the last bout of lever pressing preceding breakpoint (Figs. $1 A, 4 A, 6 A$, $7 A$ ). The increase in firing applied not only to the firing rate during lever pressing but also to firing that occurred during the RLI. This is demonstrated in Figure $3 B$, which shows average firing rates of LPE cells at three time segments during a trial: during lever pressing, in the RLI before the onset of lever pressing, and in the RLI just after receipt of the reward. All of these measures increased with each successive reward until reaching their maximum values at breakpoint. The slopes of the regression lines drawn through each of these sets of points were significantly different from $0(p<0.001)$ but not from each other (ANCOVA; $p>0.9$ ), demonstrating that firing rates in each of these intervals increased at the same rate throughout the session (Table 2). In contrast, LPI cells did not show a consistent relationship between firing rate and reward number. Firing rates both during lever pressing and around the peak during the RLI (4-5 min after reward) varied widely from their values at breakpoint, resulting in no significant difference in either of the slopes from $0(p>0.1)$ (Table 2).

The increasing firing rates of LPE cells over the session may reflect increasing IRIs. During PR experiments, IRIs increased by approximately twofold from early in the session (i.e., shortly after load up) until the reward preceding breakpoint (ANOVA; $p<$ $0.001 ; p<0.05$ for post hoc comparison of last IRI to first) (Fig. $3 A$ ). Because the highest PRs were typically well over 150 responses, it is likely that the increasing IRI was attributable to the increasing time it took for the animal to finish the required number of lever presses. This can be seen from the filled squares in Figure $3 A$, which plot RLI against number of rewards. This interval remained constant throughout the session (ANOVA; $p>0.7$ ); thus, the increasing IRI must be attributable to the time to complete the required lever presses. The constant RLIs suggest that the
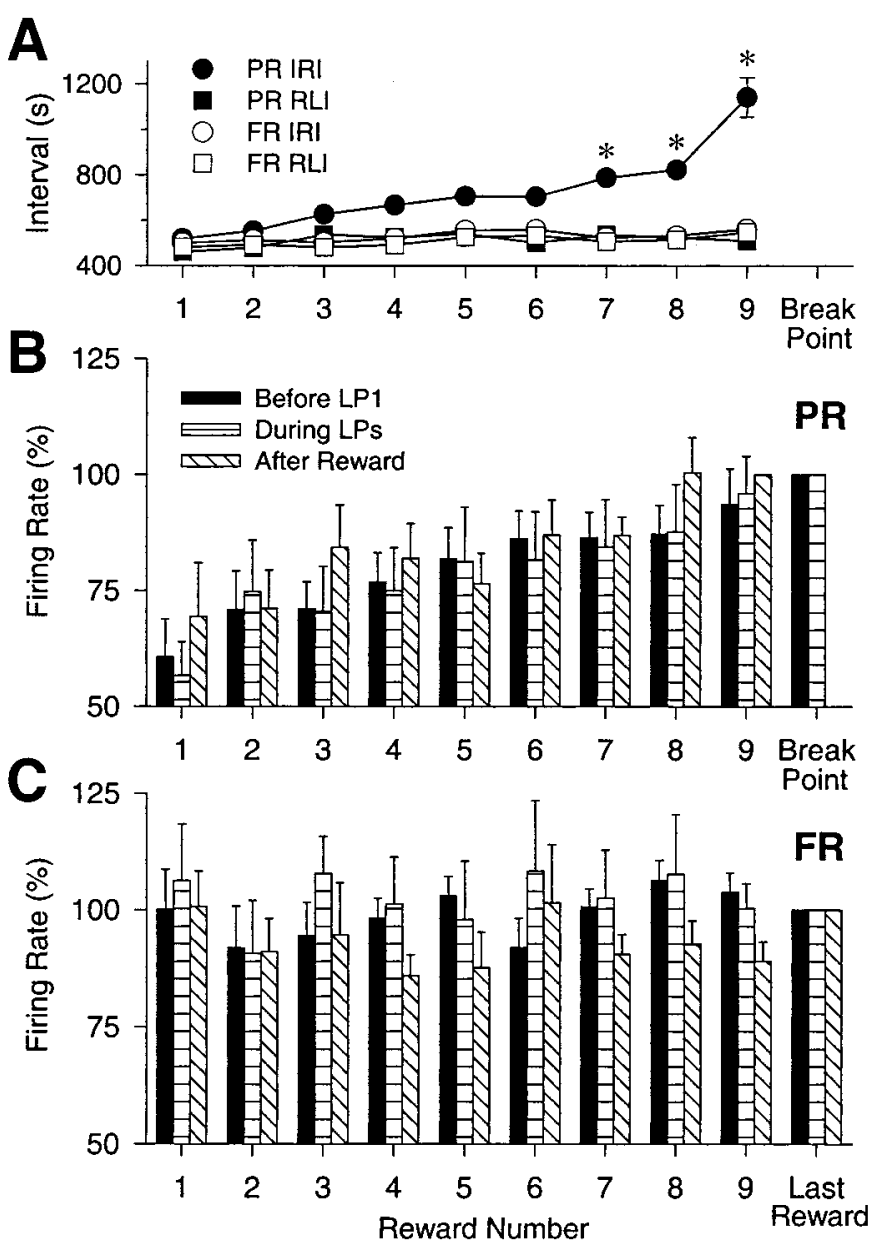

Figure 3. Comparison of fixed and progressive ratio schedules. $A$, Plot of mean IRIs (circles) and mean RLIs (squares) as a function of reward number for both PR (filled symbols) and FR (open symbols) schedules. Reward 9 corresponds to the last reward obtained before breakpoint. Two-way repeated measures ANOVA on IRIs yielded a significant effect of reward number $\left(F_{(8,535)}=6.9 ; p<0.001\right)$, as well as a significant interaction between session type (i.e., PR or FR) and reward number $\left(F_{(8,535)}=4.5\right.$; $p<0.001)$. Similar analysis of RLIs yielded $F_{(8,535)}=0.58$ and $p>0.7$ for reward number and no interaction between session type and reward number $\left(F_{(8,535)}=0.33 ; p>0.9\right)$. ${ }^{*} p<0.05$, significant difference from corresponding FR value (Student-Newman-Keuls test). Error bars in most cases are obscured by the symbols. $B$, Plot of the mean firing rate measured in three different intervals as a function of reward number. Before LP1, From 80 to $20 \mathrm{sec}$ before the first lever press; During LPs, during lever pressing; After Reward, from 20 to $80 \mathrm{sec}$ after the reward. Firing rate was normalized to the last occurrence of the interval in the session. $C$, Similar plot to $B$, but data are from FR sessions.

length of the RLI does not result from a prediction made by the animal that the time to the next reward will be greater because of the greater effort required to obtain it. Rather, the length of the RLI appears to be determined by a process time-locked to the occurrence of the previous reward.

If the increase in IRIs across the session results from the increased behavioral requirement and if the increase in IRIs is responsible for the increase in firing rates of LPE cells, then neither increasing IRI nor increasing firing rates across the session should be observed when the animals are not subject to the increasing behavioral requirement of the PR schedule. To test this hypothesis, we subjected two animals to an FR schedule in which 10 lever presses were required to receive a cocaine reward. To be certain that the increasing firing rates were not simply a function of the amount of time spent in a behavioral session, the length of these sessions was set to be substantially longer than the average length of PR sessions (154.2 \pm 5.1 min for PR sessions; at least 220 min for FR sessions). In FR experiments, no IRI was significantly 


\begin{tabular}{llll}
\hline $\begin{array}{l}\text { Table 2. Slopes of firing rates over progressive ratio and fixed ratio } \\
\text { sessions }\end{array}$ & & & \\
LPE cells & Window & Slope (PR) & Slope (FR) \\
\hline \multirow{4}{*}{ LPI Cells } & Before lever pressing & $3.50^{*}$ & -0.33 \\
& During lever pressing & $3.92^{*}$ & -0.62 \\
& After reward & $3.67^{*}$ & 0.07 \\
& Window & Slope (PR) & \\
& & & \\
& During lever pressing & 2.84 & \\
& Around peak & 1.02 &
\end{tabular}

Slope units are percent increase per reward. Asterisk indicates slope is significantly different from 0 (linear regression, $p<0.001$ ). For LPE cells, ANCOVA to compare PR slopes resulted in $F_{(2,875)}=0.054, p>0.9$, indicating that slopes did not significantly differ. ANCOVA to compare FR slopes was not performed because none of the slopes were significantly different from 0 (linear regression, $p>0.05$ ).

different from any other IRI $(p>0.05)$; thus, neither IRIs nor RLIs were increased for rewards toward the end of the session relative to early rewards (Fig. $3 A$ ). Furthermore, the slopes of the firing rates plotted against reward number for FR experiments were not significantly different from 0 for firing rates measured before lever pressing $(p>0.19)$, during lever pressing $(p>0.5)$, or after the reward $(p>0.9)$ (Fig. $3 C$, Table 2$)$. Therefore, firing rates of LPE cells during these intervals were primarily constant throughout FR sessions but increased until they reached a maximum at breakpoint during PR sessions.

One hypothesis to explain the decrease in LPE cell firing after the reward, as well as the overall increase in firing rates in PR sessions as the animal approaches breakpoint, is that cocaine causes a DA-mediated inhibition of LPE cells. According to this hypothesis, the firing rate of LPE cells should be inversely related to the instantaneous concentration of cocaine (and hence DA) within the brain; as IRIs become longer at the end of a PR session, cocaine levels during the IRI fall to lower levels. Consequently, the overall cocaine level gradually decreases and the firing rate increases. To test this hypothesis, we modeled the intra-accumbens cocaine concentration using pharmacokinetic parameters for intravenous cocaine injection. The inputs to the model that were varied were the dose of cocaine (in milligrams per kilogram) and the time at which each reward was delivered; all other parameters were constants (see Materials and Methods). Figure $4 A$ illustrates the relationship between modeled cocaine levels and the firing rate of an LPE cell. Cocaine levels fluctuated by $25-50 \%$ of their peak values, reaching local minima immediately before receipt of each cocaine reward; after the reward, the cocaine level increased rapidly and then decreased more slowly until the animal received the next reward. The rapid increase in cocaine level was accompanied by a rapid decrease in LPE cell firing rate, and the more gradual decrease in cocaine level was accompanied by a correspondingly gradual increase in firing rate. Furthermore, both the peak modeled cocaine level and the level immediately before each reward decreased with successive rewards as the IRI increased. In contrast, the modeled peak and trough levels during FR experiments were constant throughout the session. This difference is evident in Figure $4 B$, which plots the results of the model using averaged IRIs from PR and FR sessions as inputs. Thus, the increasing IRIs during the later stages of PR sessions appear to be sufficient to cause a substantial reduction in cocaine levels in the brain as the animal approaches breakpoint.

These results suggest that cocaine inhibits LPE cells and that reduction in cocaine levels toward the end of $\mathrm{PR}$ sessions releases LPE cells from cocaine-induced inhibition to achieve higher overall firing rates. Because the effects of cocaine are most likely mediated by dopamine, we sought to test the hypothesis that cocaine and dopamine influence LPE cell firing by recording from NAc cells during PR sessions in the presence DA antagonists.

\section{Effects of dopamine antagonists}

\section{SCH23390 and eticlopride effects on behavior}

It has been well established that DA antagonists reduce breakpoint in PR studies of cocaine reinforcement (Roberts et al., 1989; Hubner and Moreton, 1991; Depoortere et al., 1993; McGregor and Roberts, 1993, 1995; Richardson et al., 1994). Results from our experiments in which the D1 antagonist SCH23390 or the D2 antagonist eticlopride were administered by subcutaneous injection $30 \mathrm{~min}$ before the start of the session support these previous observations. The number of rewards obtained before breakpoint (Fig. 5A), the session length measured from the end of load up to breakpoint (Fig. $5 B$ ), and the highest number of lever presses the animal made to obtain the reward before breakpoint (data not shown) were all dose dependently reduced by SCH23390 ( $p<$ 0.002 for each ANOVA). The reduction in these measures of breakpoint was accompanied by a reduction in RLIs and IRIs. The RLI was substantially shortened at every dose of SCH23390 (ANOVA; $p<0.001$ ) (Fig. 5C). These results are consistent with the findings of earlier studies that, during FR (Koob et al., 1987; Britton et al., 1991; Corrigall and Coen, 1991; Maldonado et al., 1993; Caine and Koob, 1994a; Caine et al., 1995) and PR (Depoortere et al., 1993) experiments, the rate of cocaine intake was increased (i.e., the IRI was decreased) when the animal was administered D1 antagonists. However, despite this overall reduction in IRIs and RLIs, IRIs increased as the session progressed at all doses of the antagonist, reaching their maximum lengths just before breakpoint (Fig. $5 D$ ).

The effects of the D2 antagonist eticlopride on breakpoint, RLI, and IRI were similar to those of SCH23390. The number of rewards obtained before breakpoint (Fig. $5 A$ ), the session length (Fig. $5 B$ ), and the highest number of lever presses achieved (data not shown) were all dose dependently reduced by eticlopride $(p<$ 0.02 for each ANOVA). Furthermore, the RLI was reduced by all doses of eticlopride (ANOVA; $p<0.001$ ) (Fig. 5C). IRIs were reduced as well but still increased to their maximum values at breakpoint (Fig. 5E). Thus, D1 and D2 antagonists were remarkably similar in reducing breakpoint, IRIs, and RLIs.

Animals were observed after administration of the DA antagonists for evidence of motor effects. At the highest doses of SCH23390 and eticlopride, some sluggishness in initiating movements was observed, but animals were nevertheless able to press the lever rapidly and obtain cocaine.

\section{SCH23390 effects on LPE cell firing}

Despite the similarity in the effects of D1 and D2 antagonists on the animals' behavior during PR sessions, the antagonists differed in their effects on the firing of LPE cells. Strip charts of the firing of a typical LPE cell after exposure to SCH23390 and in the control condition (Fig. 6A-C) demonstrate the effects of SCH23390. The increase in firing rate at breakpoint is somewhat less pronounced in $\mathrm{SCH} 23390$ than in the control session; however, this reduction did not reach statistical significance when averaged over all LPE cells (Fig. 8A). ANOVAs that compared preload up, postload up, and postbreakpoint firing rates (Fig. $8 A$ ) resulted in significant overall differences between preload up and postload up firing rates, as well as significant differences between postbreakpoint and postload up firing rates. However, there were no interaction effects of $\mathrm{SCH} 23390$ on these differences in firing rate at the different times during the session, despite a general trend for the firing rates in SCH23390 to be lower at the preload up and postbreakpoint time points. Thus, SCH23390 had no effect on the decrease in firing rate that accompanies load up nor on the increase in firing rate from load up to breakpoint.

It is possible that no effect would be observed on firing rates measured at these times even if cocaine depresses LPE cell firing via a D1 receptor-dependent mechanism. The animal's behavior is clearly influenced by SCH23390, and the decreased inter-reward intervals would be expected to lead to higher cocaine levels, which might overcome the effects of the D1 antagonist. To test this possibility, we computed dose-response curves that relate LPE cell 


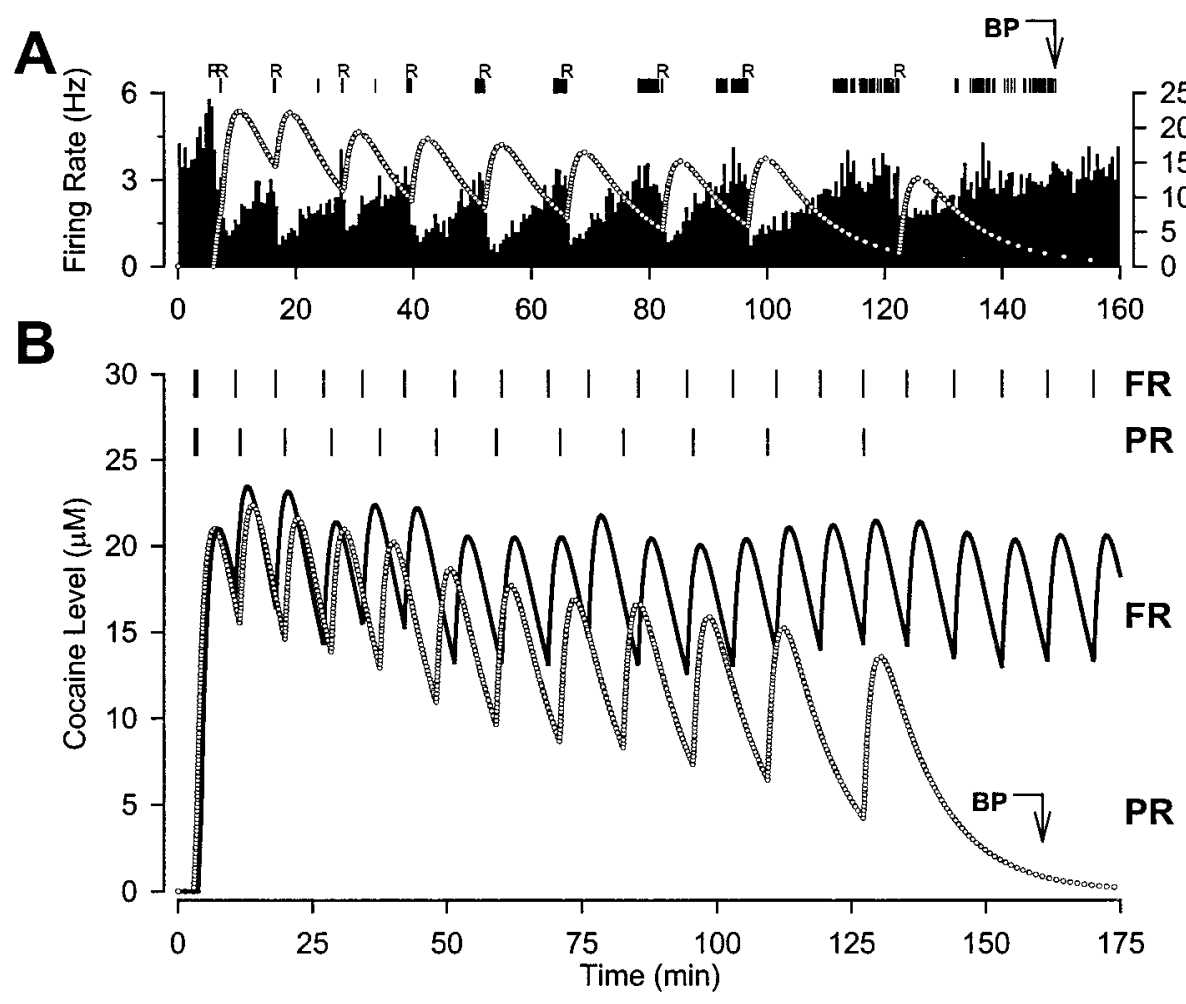

Figure 4. Modeled intra-accumbens cocaine levels fluctuate widely and are reduced to low levels at breakpoint. $A$, Strip chart histogram of the firing of an LPE cell ( filled bars) during a PR session; bin width is 30 sec. Dotted line reflects modeled cocaine levels during this experiment; inputs to the model were the times at which cocaine rewards were received during this session. Vertical dashes above the plot indicate lever presses; $R$ indicates reward. Note decrease in cocaine level with increased PR and cell firing. $B$ Comparison of modeled cocaine levels for PR (dotted line) and FR (black line) sessions. Inputs to the model depicted by these lines were the mean inter-reward intervals obtained from rats during PR and FR sessions. Load up rewards were spaced $30 \mathrm{sec}$ apart. firing rate to the modeled cocaine level and determined how these curves were affected by SCH23390 (Fig. 6D-F). Dose-response curves in the control condition show that increasing the cocaine level robustly depresses LPE cell firing rate, with maximal depression at $20 \mu \mathrm{M}$ cocaine. However, in SCH23390, the dose-response curves were flat. At the lowest cocaine levels in SCH23390, the firing rate was lower than the firing rate in vehicle control at the same levels of cocaine $(p<0.05)$, and no further decrease in firing rate was observed at higher modeled cocaine levels. ANOVAs to compare the firing rates demonstrated significant overall effects of cocaine level on the firing rate, as well as significant interaction effects of SCH23390 on the decrease in firing rate with increasing cocaine level $(p<0.001)$ (Fig. 6). Post hoc Tukey tests revealed that, within the 20 and $40 \mu \mathrm{g} / \mathrm{kg}$ doses of SCH23390, there were no significant differences among firing rates in the various cocaine levels $(p>0.05)$, whereas within the vehicle controls, firing rates at lower cocaine levels were significantly different from those at higher cocaine levels $(p<0.05)$. Therefore, $\mathrm{SCH} 23390$ reduces the firing rate of LPE cells at the lowest levels of cocaine and reduces the dependence of LPE cell firing rate on cocaine level.

This reduction by $\mathrm{SCH} 23390$ of the ability of cocaine to change LPE cell firing rate was evident when we examined firing phasicity in relation to lever pressing and reward delivery. In the vehicle control condition, the firing rates just before and during lever pressing were higher than the firing rate immediately after receipt of the cocaine reward (Fig. 8B). However, at all doses of $\mathrm{SCH} 23390$, there were significant overall reductions in firing rate compared with vehicle controls $(p<0.001)$ (Fig. $8 B)$. Although there were no interaction effects between the dose of SCH23390 and the time window, the overall reduction in firing rate by $\mathrm{SCH} 23390$ resulted in a reduction in the absolute magnitude of the differences in firing rate among prelever press, during lever press, and postreward firing (Fig. 8B).

As described earlier (Fig. 1B), LPE cell firing rates increase in the interval between each reward and the next bout of lever pressing. Because DA antagonists reduce this interval (Fig. 5C), it was important to determine how the increase in firing rate of LPE cells during the RLI was affected by DA antagonists and the reduction in length of the RLI. Slopes of the firing rate measured in $5 \mathrm{sec}$ bins from 120 to $10 \mathrm{sec}$ before the first lever press were computed for each bout of lever pressing associated with each reward (Fig. 9). This interval was used instead of the entire interval (from reward to onset of lever pressing) to compare slopes over the same time period in all doses of the antagonists, which reduced the RLI to 120-200 sec at the highest doses. To minimize the effects of changes in overall firing rates caused by the drugs, all firing rates were normalized to the rate in a $30 \mathrm{sec}$ interval beginning $40 \mathrm{sec}$ before the onset of lever pressing. Figure 9, $A$ and $B$, demonstrates that $\mathrm{SCH} 23390$ did not significantly alter the slope of the firing rate increase in the RLI $(p>0.09)$, despite the substantial reduction in the length of the RLI.

\section{Eticlopride effects on LPE cell firing}

The strip charts in Figure $7 A-C$ illustrate the effects of eticlopride on LPE cell firing in animals on the PR schedule. Preload up, postload up, and postbreakpoint firing rates were not altered by eticlopride (Fig. 8C). ANOVAs revealed no significant effects of eticlopride on firing rate and no significant interaction effects of eticlopride on the differences in firing rate caused by these different time windows (Fig. $8 C$ ). However, when firing rates were measured as a function of modeled cocaine levels, a clear rightward shift in the cocaine level-firing rate dose-response curve was observed in the presence of 20 and $40 \mu \mathrm{g} / \mathrm{kg}$ eticlopride (Fig. $7 D-F$ ). At these higher doses of eticlopride, average firing rates at every cocaine level up to $30 \mu \mathrm{M}$ were higher in eticlopride than in vehicle control $(p<0.05)$. Thus, eticlopride attenuates the reduction in LPE cell firing rate associated with increased cocaine levels.

Firing rate fluctuations around lever pressing and receipt of the reward were not substantially altered by eticlopride. In vehicle controls and all doses of eticlopride, firing rates measured before and during lever pressing were greater than immediately after receipt of the reward (Fig. $8 D$ ), although the two highest doses of eticlopride caused significant increases in overall firing rates. Because RLIs are reduced by eticlopride (Fig. 5C), the lack of effect of eticlopride on differences in firing rates measured before, during, and after lever pressing might be expected to cause an increase in the rate at which firing increases from the reward to the onset of the next bout of lever pressing. This was tested in Figure 9, $C$ and $D$, which shows that eticlopride did indeed cause a dose-dependent increase in the slope of the firing rate before the onset of lever 


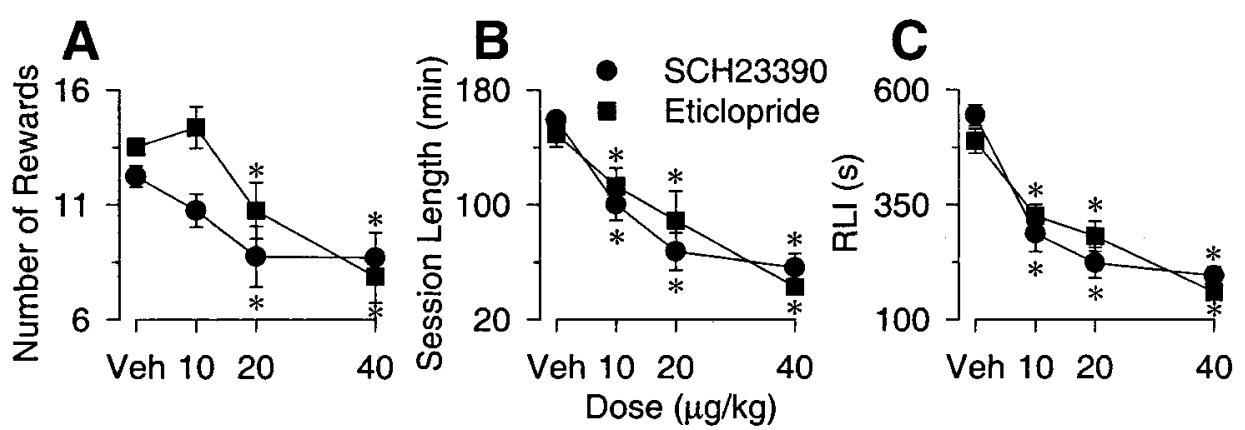

Figure 5. Behavioral effects of $\mathrm{D} 1$ and D2 antagonists given before PR sessions. $A$, The D1 antagonist SCH23390 and D2 antagonist eticlopride both reduced the mean number of rewards achieved in the session $\left(\mathrm{SCH} 23390, F_{(3.56)}=5.9, p<\right.$ 0.002 ; eticlopride, $F_{(3,60)}=10.8, p<$ $0.001)$. $B$, Both antagonists reduced the mean length of sessions, measured as time from load up to breakpoint (SCH23390, $F_{(3,56)}=38.6, p<0.001$; eticlopride, $\left.F_{(3,60)}=11.2, p<0.001\right) . C$, Both antagonists reduced the mean RLI (SCH23390, $F_{(3,55)}=34.9, p<0.001 ;$ eticlopride, $\left.F_{(3,60)}=18.9, p<0.001\right) . D, \mathrm{SCH} 23390$ reduces the mean IRI, but the IRI increases over the session even in the presence of the antagonist. $E$, Similar to $D$, for eticlopride. $B P$ indicates breakpoint. ${ }^{*} p<$ 0.05 , significant difference (Dunnett's test) from vehicle control.
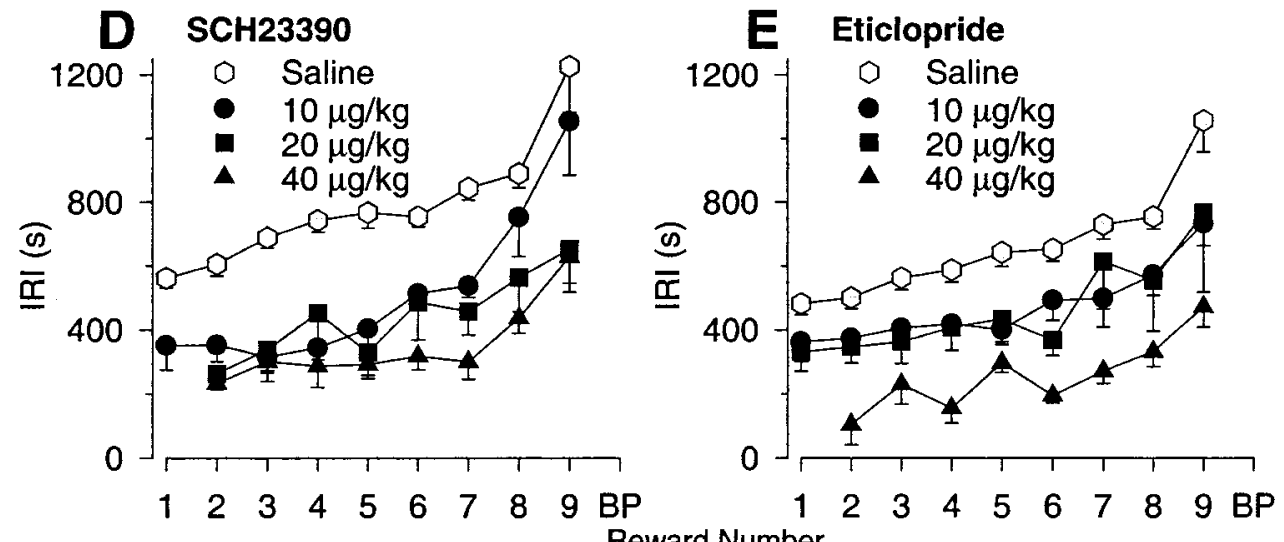

pressing $(p<0.01)$, which was significant for the highest dose $(p<$ $0.05)$. These results indicate that eticlopride accelerates the normal increase in LPE cell firing rate during the RLI, in contrast to the effects of SCH23390, which blunts the amplitude of the increase.

\section{DISCUSSION}

A clear finding of this study was that NAc cells that fire phasically during PR fall into two broad categories: LPE cells, which show increased firing rates during PR lever pressing, and LPI cells, which decrease firing rates during lever pressing. These cell types are similar to firing patterns observed previously during FR experiments (Peoples and West, 1996; Carelli and Deadwyler, 1997; Peoples et al., 1998a). We also observed the faster firing changes, occurring 0-20 sec before and after the reward, which have been described previously in detail (Carelli et al., 1993; Carelli and Deadwyler, 1994, 1996a,b; Chang et al., 1994; Peoples et al., 1997; Uzwiak et al., 1997); however, in this study, we did not analyze these short-term firing patterns.

One hypothesis to explain the rapid decrease in LPE cell firing after reward delivery is that the firing rate reflects cocaineprecipitated DA levels within the brain (Peoples and West, 1996). The firing rate of LPE cells varies systematically in inverse relation to the putative NAc cocaine level (Fig. 4) calculated using the pharmacokinetic model of Pan et al. (1991). The calculated cocaine levels have been shown to reliably predict NAc DA levels, measured with microdialysis, over a wide range of cocaine doses and interinfusion intervals (Wise et al., 1995) (see also Ranaldi et al., 1999). Although there may be subtle procedural differences between our experiments and those of Wise et al. (1995), it is unlikely that these minor factors (e.g., duration and rate of intravenous infusions) would be enough to invalidate our use of the model in this study. However, voltammetry measurements of DA levels report decreases after the rewards in psychostimulant selfadministering animals (Gratton and Wise, 1994; Kiyatkin and Stein, 1995), which complicates the assumption of a direct relationship between levels of cocaine and DA.

One intriguing issue is the extent to which the LPE cell firing pattern controls the timing of the onset of each bout of lever pressing (Peoples et al., 1998a). The remarkable regularity in IRIs of animals lever pressing for cocaine on FR schedules (Wise, 1999) has led to the development of a mathematical model to predict the time of the animal's next lever press based on the cocaine concentration within the body (Tsibulsky and Norman, 1999). The inverse correlation between cocaine level and LPE cell firing rate demonstrated here may be a mechanism by which this regularity is maintained. This idea is supported by the evidence that NAc neurons control self-administration behavior, which comes from (1) lesions of the NAc (Zito et al., 1985), (2) interruption of the DA projection to the NAc (Roberts et al., 1977; Pettit et al., 1984; Caine and Koob, 1994b), and (3) microinjections of DA antagonists directly into the NAc (Maldonado et al., 1993; McGregor and Roberts, 1993; Caine et al., 1995). Thus, the increase in LPE cell firing related to decreasing cocaine levels before onset of each bout of lever pressing may serve as a neural basis for cocaine seeking and possibly of "craving," which in human addicts reaches a peak in intensity within minutes after receipt of cocaine (O'Brien et al., 1992).

The actions of cocaine are likely to result from its blockade of DA transporters (Ritz et al., 1987), which increases extracellular DA levels in the NAc (Wise, 1999). If DA level changes produced by cocaine influence the firing rate of LPE cells, then DA antagonists should interfere with this relationship. Consistent with this prediction, eticlopride caused a rightward shift in the doseresponse function relating LPE cell firing rate to cocaine level. This result strongly implicates D2 receptors in the cocaine-involved reduction of LPE cell firing rate. The effects of D1 receptor blockade by $\mathrm{SCH} 23390$ are more difficult to interpret because of the $\mathrm{SCH} 23390$-induced overall reduction in firing rate that occurred even at very low cocaine levels (Fig. $6 D-F$ ). A potential explanation for this effect is that activation of D1 receptors (located on either NAc cells or excitatory afferent cells) by low tonic DA levels in the absence of cocaine may excite LPE cells, so that introduction of the D1 antagonist imposes an inhibitory "ceiling" effect that limits firing rate to low values.

There is growing evidence that D1 and D2 receptor activation inhibits NAc cell firing (for review, see Nicola et al., 2000). Previous electrophysiological investigation found D1 and D2 antagonistattenuated reductions in NAc cell firing immediately after cocaine 


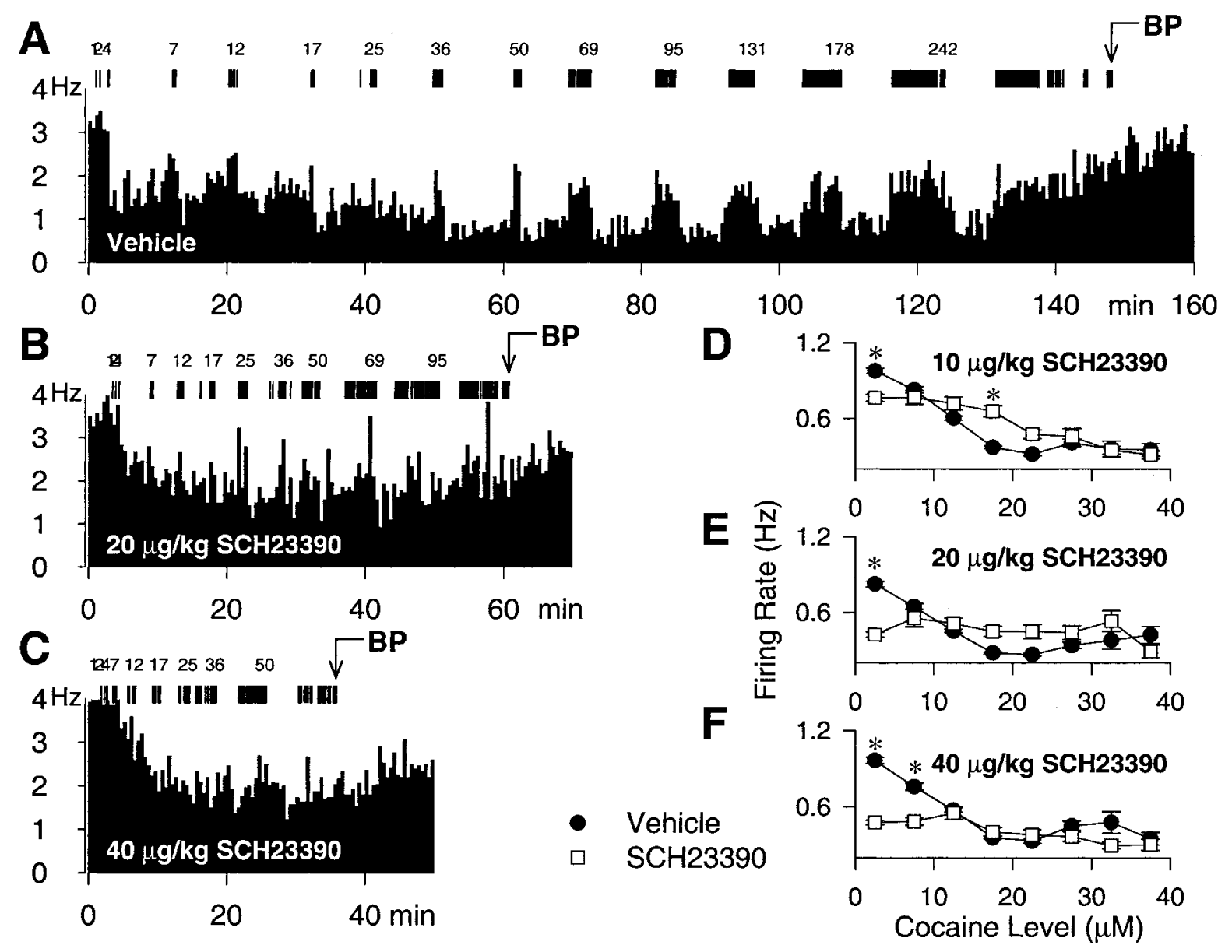

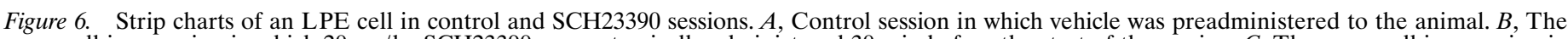

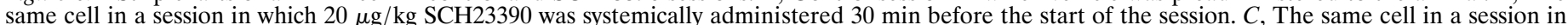

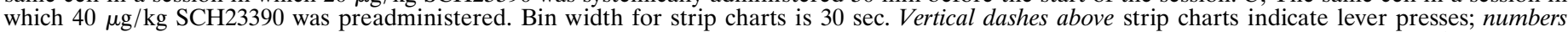

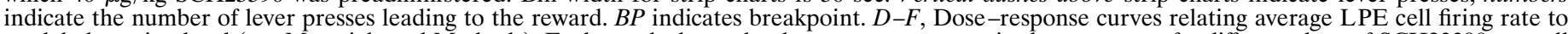

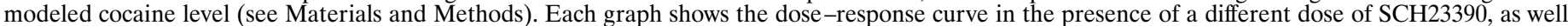

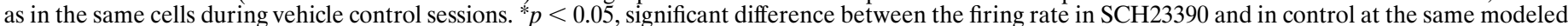

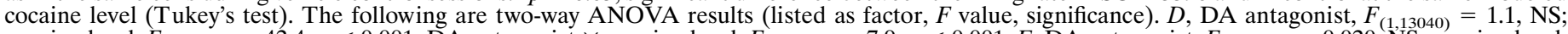

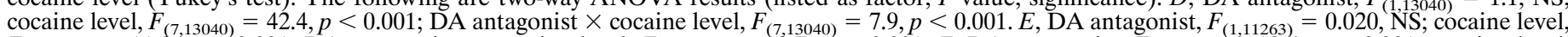

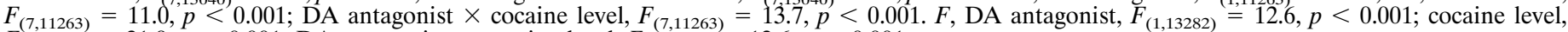
$F_{(7,13282)}=21.9, p<0.001 ;$ DA antagonist $\times$ cocaine level, $F_{(7,13282)}=12.6, p<0.001$.

delivery (Chang et al., 1994). NAc neuron recordings in anesthetized animals (White, 1987; Wachtel et al., 1989, Hu and White 1994) and awake animals (Kiyatkin and Rebec, 1996, 1997, 1999) have also demonstrated inhibitory effects of DA and DA receptor agonists, and in vitro slice experiments have found reductions in both $\mathrm{Na}^{+}$currents (Zhang et al., 1998) and excitatory synaptic transmission (Harvey and Lacey, 1996; Nicola et al., 1996; Nicola and Malenka, 1997, 1998). However, the mechanisms by which D1 and D2 receptor activation alters firing rate of NAc neurons have not been completely elucidated. Furthermore, because the drugs were systemically administered in our study, critical actions on D1 and D2 receptors may have occurred elsewhere in the brain. Growing evidence for the inhibitory effects of D1 receptor activation in the NAc (Nicola et al., 2000) suggests that the ceiling effect of SCH23390 on firing rate at low cocaine levels may be attributable to an action on cells in brain regions that excite the NAc, particularly because glutamatergic excitation is required for NAc cells to reach an activated or "up" state (Wilson, 1998).

Despite the robust effects of SCH23390 and eticlopride on the relationship between cocaine level and firing rate, variations in firing rates related to behavioral events were not markedly affected by the DA antagonists. Firing before and during lever pressing was still greater than firing after cocaine delivery at all doses of eticlopride, and the only effect of $\mathrm{SCH} 23390$ on these firing rates was an overall decrease (Fig. 8). The effects of SCH23390 are therefore readily interpretable as a consequence of the ceiling effect observed in the dose-response curve. However, the lack of a substantial effect of eticlopride on firing rate variations related to lever pressing and cocaine delivery indicates that the effective cocaine level, as indicated by firing rate, was the same for a given window regardless of the dose of eticlopride. This result is consistent with the idea that the LPE cell firing rate, which is controlled by cocaine through a D2 receptor-dependent mechanism, triggers the behavioral event (onset of lever pressing) around which these time windows are constructed. The eticlopride-induced increase in the slope of the LPE cell firing rate in the minutes preceding the onset of each bout of lever pressing provides further confirmation of this contribution of LPE cell firing to the animal's cocaine-seeking behavior.

If increases in LPE cell firing serve as a neural basis for the onset of cocaine-seeking behavior, why is such behavior still observed when the increases are severely blunted by the D1 antagonist (Fig. $8 B)$ ? Indeed, the ceiling effect on firing rates imposed by $\mathrm{SCH} 23390$ suggests that the D2-mediated changes in firing rate caused by changing cocaine levels may not influence the animal's behavior. However, some degree of firing rate fluctuation in time to reward remains in $\mathrm{SCH} 23390$. We therefore favor the hypothesis that the reduced amplitude of the fluctuations caused by blockade 


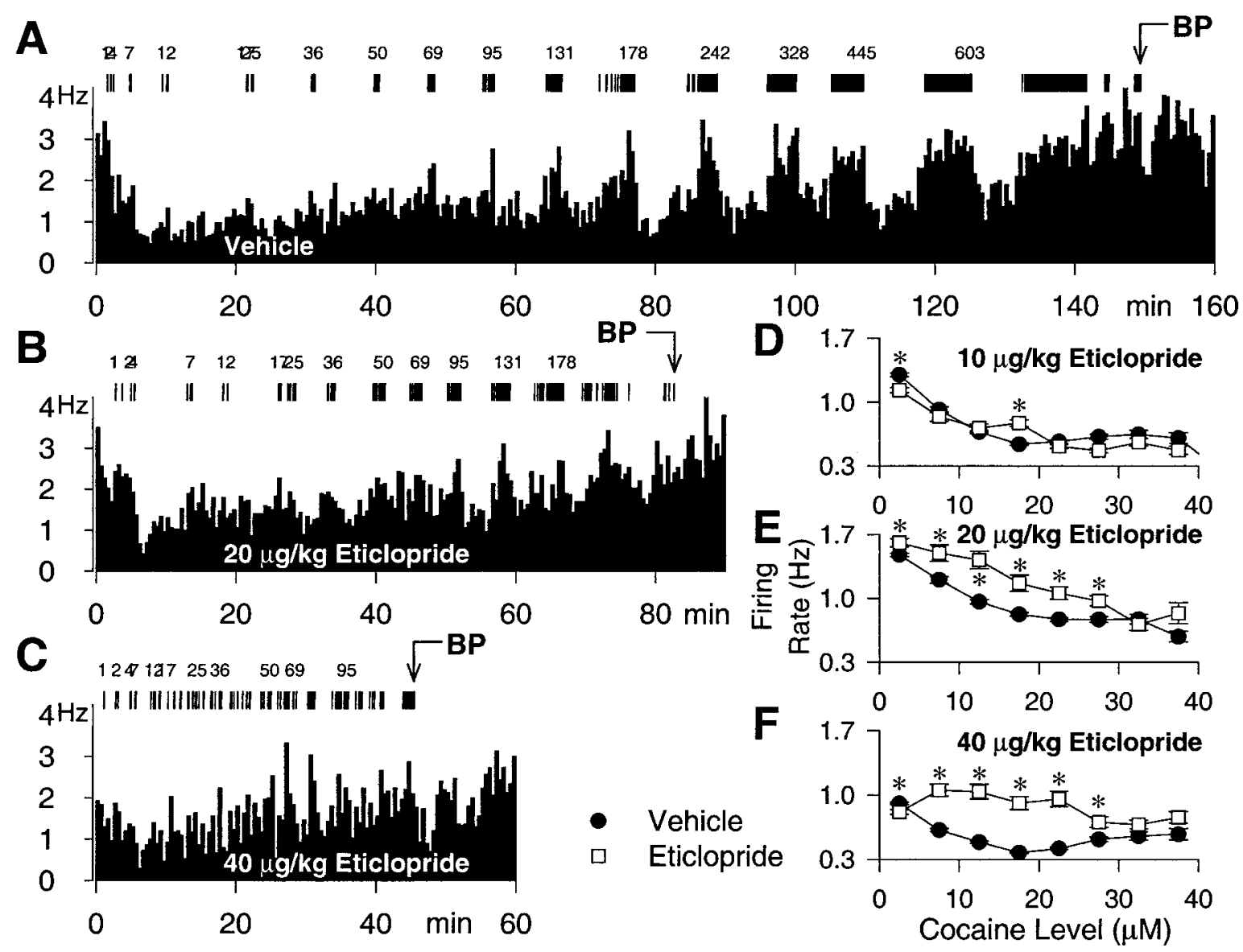

Figure 7. Strip charts of an LPE cell in control and eticlopride sessions. $A$, Control session in which vehicle was preadministered to the animal. $B$, The same cell in a session in which $20 \mu \mathrm{g} / \mathrm{kg}$ eticlopride was systemically administered $30 \mathrm{~min}$ before the start of the session. $C$, The same cell in a session in which $40 \mu \mathrm{g} / \mathrm{kg}$ eticlopride was preadministered. Bin width for strip charts is $30 \mathrm{sec}$. Vertical dashes above strip charts indicate lever presses; numbers indicate the number of lever presses leading to the reward. $B P$ indicates breakpoint. $D-F$, Dose-response curves relating average LPE cell firing rate to modeled cocaine level. Each graph shows the dose-response curve in the presence of a different dose of eticlopride, as well as in the same cells during vehicle control sessions. ${ }^{*} p<0.05$, significant difference between the firing rate in eticlopride and in control at the same cocaine level (Tukey's test). Two-way ANOVA results (listed as factor, $F$ value, significance) are as follows. $D$, DA antagonist, $\left.F_{(1} 19401\right)=2.1, \mathrm{NS} ;$ cocaine level, $F_{(7,19401)}=133.0$, $p<0.001$; DA antagonist $\times$ cocaine level, $F_{(7,19401)}=7.2, p<0.001 . E$, DA antagonist, $F_{(1,17695)}=39.8, p<0.001 ;$ cocaine level, $F_{(7,17695)}=84.8, p<$

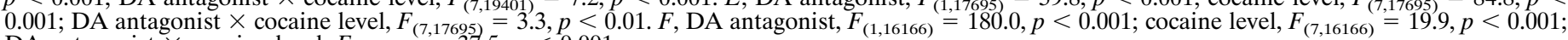
DA antagonist $\times$ cocaine level, $F_{(7,16166)}=37.5, p<0.001$.

of D1 receptors impacts the animal's behavior by reducing the RLI and breakpoint.

The present results suggest a mechanism by which breakpoint is determined: increasingly long inter-reward intervals result in progressively lower levels of DA within the NAc, which allow LPE cells to fire more rapidly and ultimately cause the animal to cease responding. Both $\mathrm{SCH} 23390$ and eticlopride reduce breakpoint, but the firing rate at breakpoint was not altered (Fig. $8 A, C$ ). We propose that the reduction in breakpoint induced by the antagonists was caused by increases in LPE cell firing rate that occurred earlier in the session than in the control condition. In the case of $\mathrm{SCH} 23390$, although there is a reduction in firing rate at lower cocaine levels, Figure $8 A$ indicates that the firing rate reaches breakpoint levels near those achieved at breakpoint in the absence of SCH23390 (although at lower PR values). In the case of eticlopride, the increased firing rate earlier in the session relative to control sessions can be explained by the eticlopride-induced rightward shift in the relationship of cocaine level to firing rate. Eticlopride antagonizes the cocaine-induced reduction of LPE firing rate, and therefore more rewards must be received in the same time to maintain the same suppression of LPE firing. To do this, the animal reduces the RLI (Fig. 5C), which increases cocaine intake; however, the IRIs required to maintain an adequate cocaine level to suppress firing are shorter than the animal can achieve, and so breakpoint is triggered earlier.

Although we suggest that there is a direct relationship between
DA levels, LPE cell firing rates, and breakpoint, it is important to note that there is much evidence against the simplistic hypothesis that dopamine levels determine how much reward the animal experiences (Berridge and Robinson, 1998). We therefore favor the view that, in the case of the cocaine-seeking animal, DA levels are critical for controlling the initiation of responding but do not influence the degree of reward experienced by the animal. We suggest that breakpoint in animals responding for psychostimulants may simply reflect the ability of the drug to maintain DA levels over the progressively longer intervals required for the animal to complete higher response-to-reward ratios. In our view, breakpoint is not a measure of the rewarding properties of the drug but instead of the degree to which DA released by the drug suppresses NAc neural activity that is responsible for the termination of drug seeking.

Our finding that the RLI remains constant throughout the cocaine PR session contrasts with the observation that RLIs increase throughout PR sessions when the reward is food and remain constant only when the NAc is lesioned (Bowman and Brown, 1998). Thus, the NAc appears to play a role in the timing of reward-seeking behaviors for both types of reward, but the mechanism used for each may be different. If indeed the large, slow fluctuations in LPE cell firing rate with cocaine self-administration are dependent on fluctuations in intra-NAc DA levels, then it is possible that much smaller and more rapid fluctuations in DA levels and firing rate may occur with more natural appetitive reinforcers 

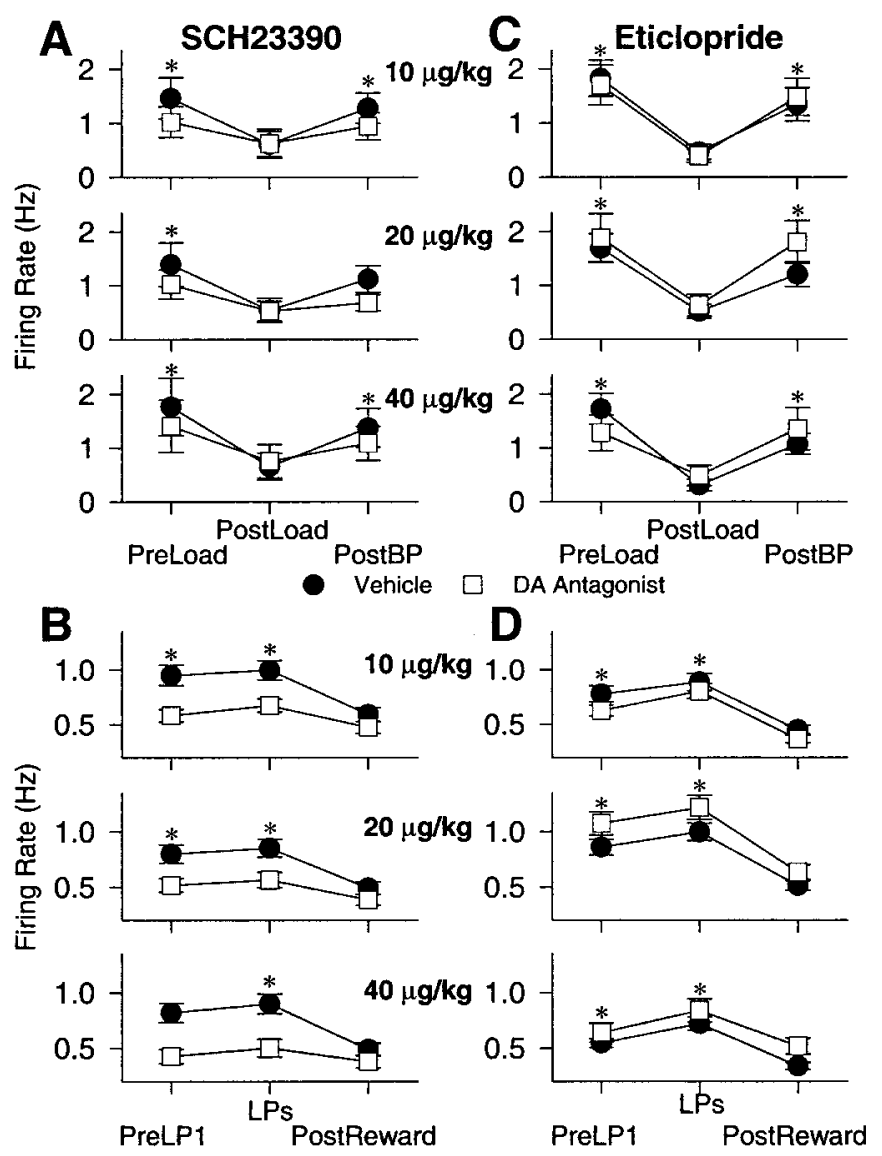

Figure 8. Effects of dopamine antagonists on LPE cell firing rate at specific times during the PR session. $A, C$, Plot of the effects of different doses of $\mathrm{SCH} 23390(A)$ and eticlopride $(C)$ on the average firing rate from the beginning of the session to the first reward (PreLoad), from 20 to $80 \mathrm{sec}$ after the reward that ends load up (PostLoad), and from 0 to $60 \mathrm{sec}$ after the last lever press of the session [i.e., postbreakpoint (PostBP)]. Open squares represent the average firing rate across all LPE cells that were recorded in the specified dose of SCH23390 or eticlopride, and filled circles represent the average of the same cells in vehicle control sessions. ${ }^{*} p<0.05$, asterisks above either PreLoad or PostBP denote an overall significant difference from PostLoad (Tukey's test). The different time windows comprise three levels of the session phase factor in two-way repeated measures ANOVAs. In no case was a significant interaction between DA antagonist and session phase found (and thus the significant differences denoted by asterisks do not differentiate between DA antagonist and vehicle control values). Results of each ANOVA comparing firing rate in DA antagonist and in vehicle controls are as follows. $\mathrm{SCH} 23390(10 \mu \mathrm{g} / \mathrm{kg})$ : DA antagonist, $F_{(1,22)}=2.4$, NS; session phase, $F_{(222)}=8.2, p<0.002 ;$ DA antagonist $\times$ session phase, $F_{(2,22)}=3.8$, NS. $\mathrm{SCH} 23390(20 \mu \mathrm{g} / \mathrm{kg}):$ DA antagonist, $F_{(1,20)}=1.5$, NS; session phase, $F_{(2,20)}=9.3, p<0.002 ;$ DA antagonist $\times$ session phase, $F_{(2,20)}=1.4, \mathrm{NS}$. $\mathrm{SCH} 23390(40 \mu \mathrm{g} / \mathrm{kg})$ : DA antagonist, $F_{(1,23)}=0.076, \mathrm{NS}$; session phase, $F_{(2,23)}=7.8, p<0.005 ;$ DA antagonist $\times$ session phase, $F_{(2,23)}=4.8$, NS. Eticlopride $(10 \mu \mathrm{g} / \mathrm{kg})$ : DA antagonist, $F_{(1,24)}=0.013$, NS; ; session phase $F_{(2,4)}=13.2, p<0.001 ;$ DA antagonist $\times$ session phase, $F_{(24)}=0.64, \mathrm{NS}$. Eticlopride $(20 \mu \mathrm{g} / \mathrm{kg})$ : DA antagonist, $F_{(1,34)}=1.8, \mathrm{NS}$; session phase $F_{(2,34)}=10.0, p<0.001$; DA antagonist $\times$ session phase, $F_{(2,34)}=1.5$, NS Eticlopride $(40 \mu \mathrm{g} / \mathrm{kg})$ : DA antagonist, $F_{(122)}=0.00086$, NS; session phase, $F_{(22)}=13.5, p<0.001 ;$ DA antagonist $\times$ session phase, $F_{(2)}=4.9$, NS There were no significant effects of DA antagonist on overall firing rates. $B$, $D$, Plot of the effects of different doses of SCH23390 $(B)$ and eticlopride $(D)$ on the average firing rate before lever pressing (PreLP1), during lever pressing $(L P s)$, and after the reward (PostReward). Intervals used to obtain the firing rates were the same as those described for Figure $3 B .{ }^{*} p<0.05$, asterisks above either PreLP1 or LPs denote a significant overall difference from PostReward (Tukey's test). In no case was a significant interaction between DA antagonist and time window found (and thus the significant differences denoted by asterisks do not differentiate between DA antagonist and vehicle control values). Results of two-way ANOVAs are as follows. SCH23390 $(10 \mu \mathrm{g} / \mathrm{kg})$ : DA antagonist, $F_{(1,726)}=20.3, p<0.001$; time window, $F_{(2.726)}=9.4, p<0.001$; DA antagonist $\times$ time window, $F_{(2,726)}=$ 1.7, NS. SCH23390 $(20 \mu \mathrm{g} / \mathrm{kg})$ : DA antagonist, $F_{(1,663)}=14.9, p<0.001$; time window, $F_{(2,663)}=8.1, p<0.001 ; \mathrm{DA}$ antagonist $\times$ time window, $F_{(2.663)}=1.0$, NS. SCH23390 $(40 \mu \mathrm{g} / \mathrm{kg}):$ DA antagonist, $F_{(1,609)}=17.6, p<$ 0.001 ; time window, $F_{(2609)}=4.9, p<0.01 ; \mathrm{DA}$ antagonist $\times$ time window, $F_{(2,609)}=1.8$, NS. Eticlopride $(10 \mu \mathrm{g} / \mathrm{kg}):$ DA antagonist, $F_{(1,930)}=4.73, \mathrm{NS}$;

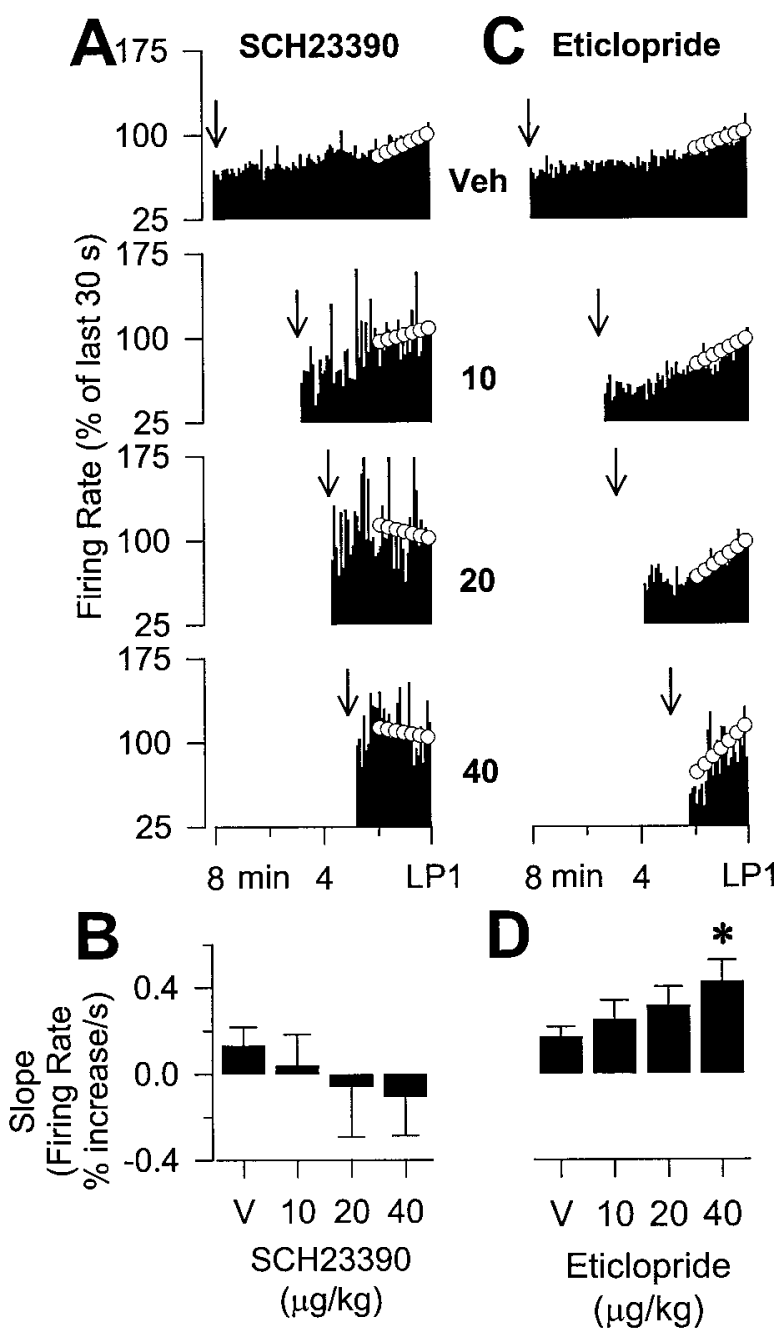

Figure 9. Effects of dopamine antagonists on the slope of the increase in firing rate of LPE cells before lever pressing. $A$, Perievent histograms $(5 \mathrm{sec}$ bin width) beginning $8 \mathrm{~min}$ before the onset of the first lever press after each reward, computed for vehicle control and all three doses of SCH23390. Arrows indicate mean time at which previous reward occurred. Histograms are averages across all cells recorded in the indicated drug and are normalized to the last $30 \mathrm{sec}$. Dotted line indicates slope computed across the 120 sec just before the first lever press. $B$, Bar graph of the mean slope of the PEH (last 120 sec before lever pressing) as a function of dose of SCH23390. Comparison of slopes with ANCOVA resulted in $F_{(31165)}=2.1$ and $p>$ 0.09 . $C, D$, Similar graphs to those in $A$ and $B$ but for eticlopride; $F_{(3,1280)}=$ $4.0, p<0.01 .{ }^{*} p<0.05$, significant difference from vehicle (Dunnett's test).

(Carelli et al., 2000). These smaller fluctuations may comprise a different timing mechanism, possibly involving different cell types. The compulsive nature of repetitive cocaine use in animals and humans may therefore result from the obliteration of the normal timing of reward seeking and its replacement by pathological timing attributable to much larger oscillations in NAc DA levels.

\section{REFERENCES}

Arnold JM, Roberts DCS (1997) A critique of fixed and progressive ratio schedules used to examine the neural substrates of drug reinforcement. Pharmacol Biochem Behav 57:441-447.

$\leftarrow$

time window, $F_{(2930)}=27.5, p<0.001 ; \mathrm{DA}$ antagonist $\times$ time window, $F_{(2,930)}=0.22$, NS. Eticlopride $(20 \mu \mathrm{g} / \mathrm{kg})$ : DA antagonist, $F_{(1,1056)}=8.1$,

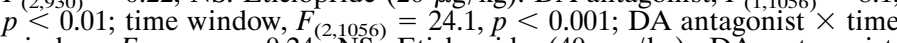
window, $F_{(2.1056)}=0.24$, NS. Eticlopride $(40 \mu \mathrm{g} / \mathrm{kg}): \mathrm{DA}$ antagonist, $F_{(1,614)}=6.3, p<0.017$; time window, $F_{(2.614)}=15.1, p<0.001 ; \mathrm{DA}$ antagonist $\times$ time window, $F_{(2,614)}=0.23$, NS. Overall firing rates were significantly lower in all doses of $\mathrm{SCH} 23390$ when compared with vehicle control, and overall firing rates were significantly higher compared with vehicle in 20 and $40 \mu \mathrm{m} / \mathrm{kg}$ eticlopride. 
Bedford JA, Bailey LP, Wilson MC (1978) Cocaine reinforced progressive ratio performance in the rhesus monkey. Pharmacol Biochem Behav 9:631-638.

Berridge KC, Robinson TE (1998) What is the role of dopamine in reward: hedonic impact, reward learning, or incentive salience? Brain Res Rev 28:309-369.

Bowman EM, Brown VJ (1998) Effects of excitotoxic lesions of the rat ventral striatum on the perception of reward cost. Exp Brain Res 123:439-448.

Britton DR, Curzon P, Mackenzie RG, Kebabian JW, Williams JEG, Kerkman D (1991) Evidence for involvement of both D1 and D2 receptors in maintaining cocaine self-administration. Pharmacol Biochem Behav 39:911-915.

Caine SB, Koob GF (1994a) Effects of dopamine D-1 and D-2 antagonists on cocaine self-administration under different schedules of reinforcement in the rat. J Pharmacol Exp Ther 270:209-218.

Caine SB, Koob GF (1994b) Effects of mesolimbic dopamine depletion on responding maintained by cocaine and food. J Exp Anal Behav 61:213-221.

Caine SB, Heinrichs SC, Coffin VL, Koob GF (1995) Effects of the dopamine D-1 antagonist SCH 23390 microinjected into the accumbens, amygdala or striatum on cocaine self-administration in the rat. Brain Res 692:47-56

Carelli RM, Deadwyler SA (1994) A comparison of nucleus accumbens neuronal firing patterns during cocaine self-administration and water reinforcement in rats. J Neurosci 14:7735-7746.

Carelli RM, Deadwyler SA (1996a) Dose-dependent transitions in nucleus accumbens cell firing and behavioral responding during cocaine selfadministration sessions in rats. J Pharmacol Exp Ther 277:385-393.

Carelli RM, Deadwyler SA (1996b) Dual factors controlling activity of nucleus accumbens cell-firing during cocaine self-administration. Synapse 24:308-311.

Carelli RM, Deadwyler SA (1997) Cellular mechanisms underlying reinforcement-related processing in the nucleus accumbens: electrophysiological studies in behaving animals. Pharmacol Biochem Behav 57:1-10

Carelli RM, King VC, Hampson RE, Deadwyler SA (1993) Firing patterns of nucleus accumbens neurons during cocaine self-administration in rats. Brain Res 626:14-22.

Carelli RM, Ijames S, Konstantopoulos J, Deadwyler SA (1999) Examination of factors mediating the transition to behaviorally correlated nucleus accumbens cell firing during cocaine self-administration in rats. Behav Brain Res 104:127-139.

Carelli RM, Ijames SG, Crumling AJ (2000) Evidence that separate neural circuits in the nucleus accumbens encode cocaine versus "natural" (water and food) reward. J Neurosci 20:4255-4266.

Chang J-Y, Sawyer SF, Lee R-S, Woodward DJ (1994) Electrophysiological and pharmacological evidence for the role of the nucleus accumbens in cocaine self-administration in freely moving rats. $\mathrm{J}$ Neurosc $14: 1224-1244$.

Corrigall WE, Coen KM (1991) Cocaine self-administration is increased by both D1 and D2 dopamine antagonists. Pharmacol Biochem Behav 39:799-802

Depoortere RY, Li DH, Lane JD, Emmett-Oglesby MW (1993) Parameters of self-administration of cocaine in rats under a progressive-ratio schedule. Pharmacol Biochem Behav 45:539-548.

Gratton A, Wise RA (1994) Drug- and behavior-associated changes in dopamine-related electrochemical signals during intravenous cocaine self-administration in rats. J Neurosci 14:4130-4146.

Green JD (1958) A simple microelectrode for recording from the central nervous system. Nature 182:962.

Griffiths RR, Brady JV, Snell JD (1978) Progressive-ratio performance maintained by drug infusions: comparison of cocaine, diethylpropion, chlorphentermine, and fenfluramine. Psychopharmacology 56:5-13.

Harvey J, Lacey MG (1996) Endogenous and exogenous dopamine depress EPSCs in rat nucleus accumbens in vitro via $\mathrm{D}_{1}$ receptor activation. J Physiol (Lond) 492:143-154.

Heimer L, Alheid GF, de Olmos J, Groenewegen HJ, Haber SN, Harlan RE, Zahm DS (1997) The accumbens: beyond the core-shell dichotomy. J Neuropsychiatry Clin Neurosci 9:354-381.

Hemby SE, Co C, Koves TR, Smith JE, Dworkin SI (1997) Differences in extracellular dopamine concentrations in the nucleus accumbens during response-dependent and response-independent cocaine administration in the rat. Psychopharmacology 133:7-16.

Hodos W (1961) Progressive ratio as a measure of reward strength. Science 134:943-944.

Hodos W, Kalman G (1963) Effects of increment size and reinforcer volume on progressive ratio performance. J Exp Anal Behav 6:387-392.

$\mathrm{Hu}$ XT, White FJ (1994) Loss of D1/D2 dopamine receptor synergisms following repeated administration of D1 or D2 receptor selective antagonists: electrophysiological and behavioral studies. Synapse 17:43-61.

Hubner CB, Moreton JE (1991) Effects of selective D1 and D2 dopamine antagonists on cocaine self-administration in the rat. Psychopharmacology 105:151-156.

Kiyatkin EA, Rebec GV (1996) Dopaminergic modulation of glutamateinduced excitations of neurons in the neostriatum and nucleus accumbens of awake, unrestrained rats. J Neurophysiol 75:142-153.

Kiyatkin EA, Rebec GV (1997) Iontophoresis of amphetamine in the neostriatum and nucleus accumbens of awake, unrestrained rats. Brain Res 771:14-24.

Kiyatkin EA, Rebec GV (1999) Striatal neuronal activity and responsiveness to dopamine and glutamate after selective blockade of D1 and D2 dopamine receptors in freely moving rats. J Neurosci 19:3594-3609.

Kiyatkin EA, Stein EA (1995) Fluctuations in nucleus accumbens dopamine during cocaine self-administration behavior: an in vivo electrochemical study. Neuroscience 64:599-617.

Koob GF, Le HT, Creese I (1987) The $\mathrm{D}_{1}$ dopamine receptor antagonist SCH 23390 increases cocaine self-administration in the rat. Neurosci Lett 79:315-320.

Li D-H, Depoortere RY, Emmett-Oglesby MW (1994) Tolerance to the reinforcing effects of cocaine in a progressive ratio paradigm. Psychopharmacology 116:326-332.

Maldonado R, Robledo P, Chover AJ, Caine SB, Koob GF (1993) D dopamine receptors in the nucleus accumbens modulate cocaine selfadministration in the rat. Pharmacol Biochem Behav 45:239-242.

McGregor A, Roberts DCS (1993) Dopaminergic antagonism within the nucleus accumbens or the amygdala produces differential effects on intravenous cocaine self-administration under fixed and progressive ratio schedules of reinforcement. Brain Res 624:245-252.

McGregor A, Roberts DCS (1995) Effect of medial prefrontal cortex injections of SCH 23390 on intravenous cocaine self-administration under both a fixed and progressive ratio schedule of reinforcement. Behav Brain Res 67:75-80.

McGregor A, Baker G, Roberts DCS (1996) Effect of 6-hydroxydopamine lesions of the medial prefrontal cortex on intravenous cocaine selfadministration under a progressive ratio schedule of reinforcement. Pharmacol Biochem Behav 53:5-9.

Nicola SM, Malenka RC (1997) Dopamine depresses excitatory and inhibitory synaptic transmission by distinct mechanisms in the nucleus accumbens. J Neurosci 17:5697-5710.

Nicola SM, Malenka RC (1998) Modulation of synaptic transmission by dopamine and norepinephrine in ventral but not dorsal striatum. J Neurophysiol 79:1768-1776.

Nicola SM, Kombian SB, Malenka RC (1996) Psychostimulants depress excitatory synaptic transmission in the nucleus accumbens via presynaptic D1-like dopamine receptors. J Neurosci 16:1591-1604.

Nicola SM, Surmeier DJ, Malenka RC (2000) Dopaminergic modulation of neuronal excitability in the striatum and nucleus accumbens. Annu Rev Neurosci 23:185-215.

O'Brien CP, Childress AR, McLellan AT, Ehrman R (1992) Classical conditioning in drug-dependent humans. Ann NY Acad Sci 654:400-415.

Pan H-T, Menacherry S, Justice Jr JB (1991) Differences in the pharmacokinetics of cocaine in naive and cocaine-experienced rats. J Neurochem 56:1299-1306.

Paxinos G, Watson C (1986) The rat brain in stereotaxic coordinates. New York: Academic.

Peoples LL, West MO (1996) Phasic firing of single neurons in the rat nucleus accumbens correlated with the timing of intravenous cocaine self-administration. J Neurosci 16:3459-3473.

Peoples LL, Uzwiak AJ, Gee F, West MO (1997) Operant behavior during sessions of intravenous cocaine infusion is necessary and sufficient for phasic firing of single nucleus accumbens neurons. Brain Res 757:280-284.

Peoples LL, Gee F, Bibi R, West MO (1998a) Phasic firing time locked to cocaine self-inf usion and locomotion: dissociable firing patterns of single nucleus accumbens neurons in the rat. J Neurosci 18:7588-7598.

Peoples LL, Uzwiak AJ, Guyette FX, West MO (1998b) Tonic inhibition of single nucleus accumbens neurons in the rat: a predominant but not exclusive firing pattern induced by cocaine self-administration sessions. Neuroscience 86:13-22.

Pettit HO, Justice JB (1989) Dopamine in the nucleus accumbens during cocaine self-administration as studied by in vivo microdialysis. Pharmacol Biochem Behav 34:899-904.

Pettit HO, Ettenberg A, Bloom FE, Koob GF (1984) Destruction of dopamine in the nucleus accumbens selectively attenuates cocaine but not heroin self-administration in rats. Psychopharmacol 84:167-173.

Ranaldi R, Pocock D, Zereik R, Wise RA (1999) Dopamine fluctuations in the nucleus accumbens during maintenance, extinction and reinstatement of intravenous D-amphetamine self-administration. J Neurosci 19:4102-4109.

Richarson NR, Roberts DCS (1996) Progressive ratio schedules in drug self-administration studies in rats: a method to evaluate reinforcing efficacy. J Neurosci Methods 66:1-11.

Richardson NR, Smith AM, Roberts DCS (1994) A single injection of either flupenthixol decanoate or haloperidol decanoate produces longterm changes in cocaine self-administration in rats. Drug Alcohol Depend 36:23-25.

Risner ME, Cone EJ (1986) Intravenous self-administration of fencamfamine and cocaine by beagle dogs under fixed-ratio and progressiveratio schedules of reinforcement. Drug Alcohol Depend 17:93-101.

Risner ME, Goldberg SR (1983) A comparison of nicotine and cocaine self-administration in one dog: fixed-ratio and progressive-ratio schedules of intravenous drug infusion. J Pharmacol Exp Ther 224:319-326.

Risner ME, Silcox DL (1981) Psychostimulant self-administration by beagle dogs in a progressive-ratio paradigm. Psychopharmacology 75:25-30. 
Ritz MC, Lamb RJ, Goldberg SR, Kuhar MJ (1987) Cocaine receptors on dopamine transporters are related to self-administration of cocaine. Science 237:1219-1223.

Roberts DCS, Corcoran ME, Fibiger HC (1977) On the role of ascending catecholaminergic systems in intravenous self-administration of cocaine. Pharmacol Biochem Behav 6:615-620.

Roberts DCS, Loh EA, Vickers G (1989) Self-administration of cocaine on a progressive ratio schedule in rats: dose-response relationship and effect of haloperidol pretreatment. Psychopharmacology 97:535-538.

Smith A, Piercey M, Roberts DCS (1995) Effect of (-)-DS 121 and (+)-UH 232 on cocaine self-administration in rats. Psychopharmacology 120:93-98.

Tsibulsky VL, Norman AB (1999) Satiety threshold: a quantitative model of maintained cocaine self-administration. Brain Res 839:85-93.

Uzwiak AJ, Guyette FX, West MO, Peoples LL (1997) Neurons in accumbens subterritories of therat: phasic firing time-locked within seconds of intravenous self-infusion. Brain Res 767:363-369.

Wachtel SR, Hu X-T, Galloway MP, White FJ (1989) D1 dopamine receptor stimulation enables the postsynaptic, but not autoreceptor, effects of D2 dopamine agonists in nigrostriatal and mesoaccumbens dopamine systems. Synapse 4:327-346.
White FJ (1987) D-1 dopamine receptor stimulation enables the inhibition of nucleus accumbens neurons by a D-2 receptor agonist. Eur J Pharmacol 135:101-105.

Wilson C J (1998) Basal ganglia. In: The synaptic organization of the brain (Shepherd GM, ed), pp 329-375. New York: Oxford UP.

Winger G, Woods JH (1985) Comparison of fixed-ratio and progressiveratio schedules of maintenance of stimulant drug-reinforced responding. Drug Alcohol Depend 15:123-130.

Wise RA (1999) Cognitive factors in addiction and nucleus accumbens function: some hints from rodent models. Psychobiology 27:300-310.

Wise RA, Newton P, Leeb K, Burnette B, Pocock D, Justice JB (1995) Fluctuations in nucleus accumbens dopamine concentration during intravenous cocaine self-administration in rats. Psychopharmacology 120:10-20.

Zar JH (1974) Biostatistical analysis. Englewood Cliffs, NJ: Prentice Hall. Zhang X-F, Hu X-T, White FJ (1998) Whole-cell plasticity in cocaine withdrawal: reduced sodium currents in nucleus accumbens neurons. J Neurosci 18:488-498.

Zito KA, Vickers G, Roberts DCS (1985) Disruption of cocaine and heroin self-administration following kainic acid lesions of the nucleus accumbens. Pharmacol Biochem Behav 23:1029-1036. 